\title{
Black rice (Oryza sativa L.) extract modulates ultraviolet-induced expression of matrix metalloproteinases and procollagen in a skin cell model
}

\author{
MIRA HAN ${ }^{1-3 *}$, JUNG-SOO BAE ${ }^{1-3 *}$, JAE-JUN BAN ${ }^{2,3}$, HEE SOON SHIN ${ }^{4}$, \\ DONG HUN LEE ${ }^{2,3}$ and JIN HO CHUNG ${ }^{1-3}$ \\ ${ }^{1}$ Department of Biomedical Sciences, Seoul National University Graduate School; ${ }^{2}$ Department of Dermatology, \\ Seoul National University College of Medicine; ${ }^{3}$ Institute of Human-Environment Interface Biology, \\ Medical Research Center, Seoul National University, Seoul 110-744; ${ }^{4}$ Korea Food \\ Research Institute, Seongnam-si, Gyeonggi-do 463-746, Republic of Korea
}

Received December 29, 2016; Accepted February 13, 2018

DOI: $10.3892 /$ ijmm.2018.3508

\begin{abstract}
Exposure of the skin to ultraviolet (UV) radiation causes extracellular matrix (ECM) collapse in the dermis, owing to an increase in matrix metalloproteinase (MMP) production in both the epidermis and dermis, and a decrease in type I collagen expression in the dermis. Recently, black rice (Oryza sativa L.) was reported to have a wide range of pharmacological effects in various settings. However, the effects of black rice extract (BRE) on UV-irradiated skin cells have not yet been characterized. BRE treatment did not affect cell morphology and viability of $\mathrm{HaCaT}$ and human dermal fibroblasts (HDF). We demonstrated that BRE downregulated basal and UV-induced MMP-1 expression in HaCaT cells. Furthermore, BRE significantly increased type I procollagen expression, and decreased MMP-1 and MMP-3 expression in UV-irradiated HDF. The underlying mechanisms of these results involve a decrease in p38 and c-Jun N-terminal kinase activity, and suppression of UV-induced activation of activator protein-1 (AP-1). BRE reduced UV-induced reactive oxygen species production in $\mathrm{HaCaT}$ cells in a dose-dependent manner. Indeed, mass spectrometry revealed that BRE contained antioxidative flavonoid components such as cyanidin-3-O- $\beta$-D-glycoside and taxifolin-7-O-glucoside.
\end{abstract}

Correspondence to: Professor Jin Ho Chung or Professor Dong Hun Lee, Department of Dermatology, Seoul National University College of Medicine, 101 Daehak-ro, Jongno-gu, Seoul 110-744, Republic of Korea

E-mail: jhchung@snu.ac.kr

E-mail: ivymed27@snu.ac.kr

*Contributed equally

Key words: black rice, matrix metalloproteinases, type I procollagen, reactive oxygen species, activator protein-1, mitogen-activated protein kinase
These findings suggest that BRE attenuates UV-induced ECM damage by modulating mitogen-activated protein kinase and AP-1 signaling, and could be used as an active ingredient for preventing photoaging of the skin.

\section{Introduction}

During an individual's lifetime, human skin is continuously exposed to harmful environmental factors, such as ultra violet (UV) light. Even though UV light stimulates the synthesis of vitamin D (1), which has beneficial effects in terms of regulating the immune system and calcium homeostasis, excessive UV exposure can cause oxidative damage $(2,3)$, immune suppression (4), collagen degradation $(5,6)$, photoaging, and skin cancer (7-9). UV irradiation induces the synthesis of matrix metalloproteinases (MMPs) in the skin $(5,6,10)$. MMPs are a family of zinc-dependent endopeptidases that play a major role in extracellular matrix (ECM) degradation, including collagen fibers. More specifically, UV induces activation of mitogen-activated protein kinase (MAPK) components, such as extracellular signal-regulated kinase (ERK), c-Jun N-terminal kinase (JNK), and p38 MAPK (p38), which in turn regulate activator protein-1 (AP-1), leading to increased MMPs expression, and decreased collagen production $(10,11)$.

Black rice is a grain from the species Oryza sativa L. var. japonica. It contains various polyphenolic compounds, such as anthocyanins (12), which have antioxidative activity. It has been reported that black rice extract (BRE) has many pharmacological effects, including antioxidant (13) and anti-inflammatory (14-16) activity. Furthermore, black rice anthocyanin extracts have been studied in various types of cancer, and have been shown to suppress cancer cell invasion (17), metastasis (18), and angiogenesis (19,20). Additionally, black rice bran inhibits tyrosinase activity in cell-free in vitro systems, suggesting its potential as a melanogenesis inhibitor (21). Germinated black rice also enhances hyaluronan production in HaCaT keratinocytes (22). However, it remains unknown whether BRE prevents UV-induced ECM alteration. Therefore, the aim of the present study was to 
investigate the effects of BRE in UV-irradiated $\mathrm{HaCaT}$ cells, and human dermal fibroblasts (HDF), by analyzing the expression of MMPs and collagen, and generation of reactive oxygen species (ROS), as well as the underlying signaling pathways involved.

\section{Materials and methods}

Reagents and antibodies. 3-(4,5-dimethylthiazol-2-yl)-2, 5-diphenyltetrazolium bromide (MTT), 2'7'-dichlorofluorescein diacetate (DCF-DA), $N$-Acetyl-L-cysteine (NAC) and phosphatase inhibitor cocktail were obtained from Sigma-Aldrich (St. Louis, MO, USA). Protease inhibitor cocktail tablets were purchased from Roche Applied Science (Penzberg, Germany). Anti-MMP-1 antibody (Oncogene Research Products, Boston, MA, USA) and monoclonal anti-procollagen type I N-terminal extension peptide (SP1.D8) antibody (Developmental Studies Hybridoma Bank, Iowa City, IA, USA) were used. Phospho- ERK1/2, JNK, p38 MAPK, and c-Jun, and the total ERK1/2, JNK, p38 MAPK, and c-Jun were purchased from Cell Signaling Technology, Inc. (Beverly, MA, USA). Anti-c-Fos, $\beta$-actin and lamin B were purchased from Santa Cruz Biotechnology, Inc. (Santa Cruz, CA, USA).

Preparation of BRE. BRE was prepared, and provided by the Korea Food Research Institute (Seongnam-si, Korea). Briefly, whole grains of black rice were extracted with $50 \%$ ethanol using a microwave system. The ethanol solvent was then evaporated using a freeze dryer (yield: $2.68 \%$ of dry wt). Stock solutions of BRE were prepared by dissolving the powder in DMSO, and stored at $-20^{\circ} \mathrm{C}$. The final concentration of DMSO in the medium was kept below $0.1 \%$.

Cell line and culture conditions. Two types of cells were used in this study: $\mathrm{HaCaT}$ cells, which is a spontaneously transformed human keratinocyte cell line and primary HDF, isolated from the foreskin of young volunteers (aged 10-19 years). The present study was approved by the Institutional Review Board (IRB no. 1101-116-353) at Seoul National University Hospital and conducted according to the Declaration of Helsinki. All subjects provided written informed consent. HaCaT (immortalized human keratinocytes) and HDF between fifth to fifteenth passages were used for all experiments. The $\mathrm{HaCaT}$ cells and HDF were maintained in Dulbecco's modified Eagle's medium (DMEM; Welgene, Daegu, Korea) containing $10 \%$ fetal bovine serum (FBS; Welgene) and penicillin/streptomycin $(400 \mathrm{U} / \mathrm{ml}, 50 \mathrm{~g} / \mathrm{l})$ at $37^{\circ} \mathrm{C}$ in a humidified condition with $5 \% \mathrm{CO}_{2}$.

UV irradiation and BRE treatment. The cells were starved of media for $24 \mathrm{~h}$, and washed twice and replaced with PBS prior to UV irradiation. Philips TL 20W/12 RS fluorescent sun lamps with an emission spectrum between 275 and $380 \mathrm{~nm}$ (peak, 310-315 nm) were used as the UV source, as previously described (23). To block UVC ( $<290 \mathrm{~nm})$ wavelengths, Kodacel filter (TA401/407; Kodak, Rochester, NY, USA) was placed $2 \mathrm{~cm}$ in front of UV lamp. Waldmann UV meter (model 585100, Villingen-Schwenningen, Germany) was used to measure UV irradiance. Immediately after UV irradiation ( $\mathrm{HaCaT}$ cell; $50 \mathrm{~mJ} / \mathrm{cm}^{2}$, HDF; $100 \mathrm{~mJ} / \mathrm{cm}^{2}$ ), PBS was replaced with serum-free media with or without BRE for indicated time periods.

MTT assay. The cell viability was measured by MTT assay. The HaCaT $\left(2 \times 10^{4}\right.$ cells/well) and HDF $\left(5 \times 10^{4}\right.$ cells/well $)$ cells were seeded into 96-well plates and were maintain until $80 \%$ confluency, and then cells were UV-irradiated or non-irradiated. The cells were post-treated with various concentrations of BRE for $48 \mathrm{~h}$. After incubation, MTT solution $(0.5 \mathrm{mg} / \mathrm{ml}$ in PBS) was added into culture plates and further incubated for $4 \mathrm{~h}$. The formazan crystals were dissolved in DMSO after culture media was removed and were quantified at $570 \mathrm{~nm}$ using ELISA reader (Thermo Fisher Scientific, Waltham, MA, USA).

Nuclear protein extraction. HaCaT cells were scraped from culture dishes, suspended in ice-cold cytoplasmic extraction buffer (20 mM Tris, $1.5 \mathrm{mM} \mathrm{MgCl} 2,10 \mathrm{mM} \mathrm{KCl}, 0.2 \mathrm{mM}$ EDTA, $0.5 \mathrm{mM}$ DTT, $0.5 \%$ Nonidet P-40, protease inhibitor cocktail) and incubated on ice for $10 \mathrm{~min}$. Subsequently, nuclear pellets were collected by centrifugation at $6,000 \mathrm{rpm}$ for $5 \mathrm{~min}$ at $4^{\circ} \mathrm{C}$ and were re-suspended with extraction buffer (cytoplasmic extraction buffer with $400 \mathrm{mM} \mathrm{NaCl}$, $5 \%$ glycerol) and incubated on ice for $30 \mathrm{~min}$ with shaking. The pellets were centrifuged at $12,000 \mathrm{rpm}$ for $10 \mathrm{~min}$ at $4^{\circ} \mathrm{C}$ to obtain the nuclear fraction.

Western blot analysis. To determine the amount of MMPs and procollagen secreted into the culture medium, equal amounts of culture medium were separated using polyacrylamide gel electrophoresis, and then the separated proteins were electro-transferred onto a PVDF membrane (Amersham, Buckinghamshire, UK). The membrane was blocked with blocking buffer, and then incubated with appropriate primary antibodies. After incubation, the membranes were washed, then incubated with horseradish peroxidase-conjugated secondary antibody. Enhanced chemiluminescence detection system (GE Healthcare) was used to visualize the protein bands. To analyze MAPK signaling, HaCaT cells were lysed with RIPA lysis buffer (Millipore Corp., Billerica, MA, USA) containing protease and phosphatase inhibitors. Furthermore, to analyze AP-1 activation, the nuclear proteins were extracted from the cells as described above.

Reverse transcription and real-time quantitative $P C R$ $(R T-q P C R)$. RNAiso Plus (Takara Bio Inc., Shiga, Japan) was used to isolate the total RNA from the HaCaT cells and HDF (24). Isolated total RNA (1 $\mu \mathrm{g})$ was used as templates for cDNA synthesis using a First Strand cDNA Synthesis kit (MBI Fermentas, Vilnius, Lithuania) according to the manufacturer's instructions, which was then used for real-time PCR. The PCR cycling conditions were $50^{\circ} \mathrm{C}$ for 2 min and $95^{\circ} \mathrm{C}$ for $2 \mathrm{~min}$, followed by 40 cycles at $95^{\circ} \mathrm{C}$ for $15 \mathrm{sec}$ and $60^{\circ} \mathrm{C}$ for $1 \mathrm{~min}$. Quantitation of PCR reactions was performed by 7500 Real-time PCR System (Applied Biosystems Life Technologies, Foster City, CA, USA) with the SYBR Premix Ex Taq II kit (Takara Bio Inc.) using suitable primers as follows: hMMP-1 forward, 5'-AAGCGTGTGACAGTAAGCTA-3' and reverse, 5'-AACCGGACTTCATCTCTG-3', hMMP-3 forward, 5'-CTCACAGACCTGACTCGGTT 3 ' and reverse, 
A

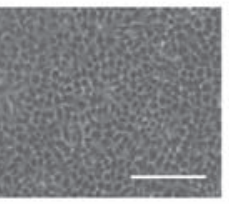

BRE

$-$

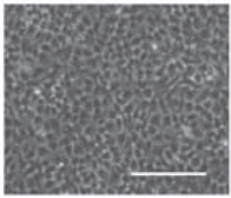

$100 \mu \mathrm{g} / \mathrm{ml}$

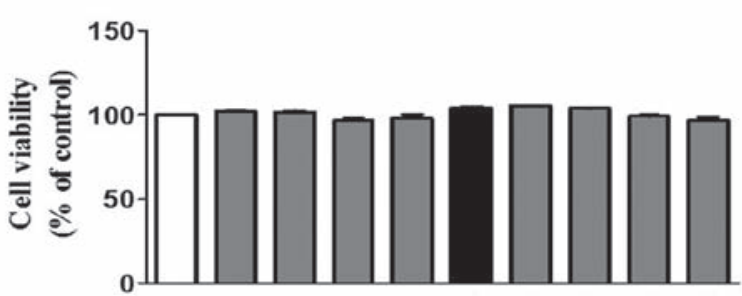

$\mathrm{UV}\left(50 \mathrm{~mJ} / \mathrm{cm}^{2}\right) \quad-\quad-\quad-\quad+\quad++++$

$\operatorname{BRE}(\mu \mathrm{g} / \mathrm{ml}) \quad-\quad \begin{array}{lllllllll}1 & 5 & 25 & 100 & - & 1 & 5 & 25 & 100\end{array}$

B

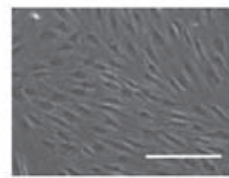

BRE

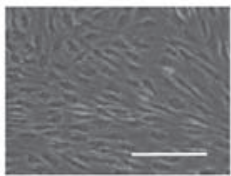

$100 \mu \mathrm{g} / \mathrm{ml}$

Figure 1. Effects of BRE and UV irradiation on the cell viability in HaCaT cells and HDF. Cell morphology and viability were examined in (A) HaCaT cells and (B) HDF treated with the indicated concentration of BRE without or with UV irradiation $\left(50 \mathrm{~mJ} / \mathrm{cm}^{2} \mathrm{and} 100 \mathrm{~mJ} / \mathrm{cm}^{2}\right.$ for HaCaT cells and $\mathrm{HDF}$, respectively). The optical densities were measured and the percentage of viability was calculated. Values are mean \pm SEM of four independent experiments. Scale bar indicates $200 \mu \mathrm{m}$. BRE, black rice extract; UV, ultraviolet; HDF, human dermal fibroblasts.

5'-CACGCCTGAAGGAAGAGATG-3', h type I procollagen forward, 5'-CTCGAGGTGGACACCACCCT-3' and reverse, 5'-CAGCTGGATGGCCACATCGG-3' h36B4 forward, 5'-TCGACAATGGCAGCATCTAC-3' and reverse, 5'-TGATGCAACAGTTGGGTAGC-3'. Relative mRNA expression was analyzed using the $2^{-\Delta \Delta \mathrm{Ct}}$ methods, and $36 \mathrm{~B} 4$ was used as an internal control. Data are expressed as the fold number of gene expression.

Measurement of ROS production. To quantify intracellular oxidative stress, the cells were pretreated with NAC $(2 \mu \mathrm{M})$ or BRE for $1 \mathrm{~h}$, and then washed with PBS. After washing, the cells were labeled with $20 \mathrm{mM}$ DCF-DA at $37^{\circ} \mathrm{C}$ for $1 \mathrm{~h}$. To induce ROS generation, the cells were exposed to UV irradiation at a dose of $50 \mathrm{~mJ} / \mathrm{cm}^{2}$. The cells were then washed twice with PBS, and the relative ROS level was determined using a Victor3 multilabel plate reader (PerkinElmer, Inc., Waltham, MA, USA), with an excitation wavelength of $485 \mathrm{~nm}$ and an emission wavelength of $535 \mathrm{~nm}$. At the same time, fluorescence images were captured under a fluorescence microscope (DMIL; Leica Microsystems GmbH, Wetzlar, Germany) with a 20x0.75 NA objective lens.

Ultra performance liquid chromatography-quadrupole-time of flight (UPLC-Q-TOF) mass spectrometry (MS). To identify black rice metabolites, metabolites from $50 \%$ ethanolic extract of black rice were analyzed by an ultra performance liquid chromatography-quadrupole-time of flight (UPLC-Q-TOF) MS (Waters Corp., Milford, MA, USA). The extract was injected into an Acquity UPLC BEH C18 column (2.1x100 mm, $1.7 \mu \mathrm{m}$; Waters Corp.) at a column temperature of $40^{\circ} \mathrm{C}$. Mobile phase consisted of water with $0.1 \%$ formic acid (FA) and aceto- nitrile with $0.1 \% \mathrm{FA}$ at a flow rate of $0.35 \mathrm{ml} / \mathrm{min}$ for $9 \mathrm{~min}$. The eluents were ionized by electrospray ionization (ESI) with positive or negative mode and analyzed using a Q-TOF MS. The scan range of TOF MS data was from 50 to $1,500 \mathrm{~m} / \mathrm{z}$ with a scan time of $0.2 \mathrm{sec}$. The capillary voltage was set at 3 or $2.5 \mathrm{kV}$ for positive mode and negative mode, respectively, while the sample cone voltage was $40 \mathrm{~V}$. The desolvation flow rate was $900 \mathrm{l} / \mathrm{h}$ at a temperature of $400^{\circ} \mathrm{C}$ and source temperature set to $100^{\circ} \mathrm{C}$. Leucine-enkephalin $([\mathrm{M}+\mathrm{H}]=\mathrm{m} / \mathrm{z}$ 556.2771) was used as a reference for lock mass at a frequency of $10 \mathrm{sec}$. The MS/MS spectra were obtained using collision energy ramps from 20 to $45 \mathrm{eV}$. Metabolites were identified by Unifi software with various LC/MS databases.

Statistical analysis. The results are presented as means \pm SEM, and statistical analyses were performed using a Student's t-test or one-way ANOVA. $\mathrm{P}<0.05$ was considered to indicate a statistically significant difference.

\section{Results}

Effects of BRE on cell viability in HaCaT and HDF. To examine the effect of BRE on skin cells, we first tested the cytotoxicity of BRE using an MTT assay. BRE $(5-100 \mu \mathrm{g} / \mathrm{ml})$ did not influence the viability of $\mathrm{HaCaT}$ cells, with or without UV irradiation (Fig. 1A). A slight, but not significant, reduction in the viability of HDF was observed after treatment with $5-100 \mu \mathrm{g} / \mathrm{ml}$ of BRE (Fig. 1B). Under the same experimental conditions, $100 \mu \mathrm{g} / \mathrm{ml}$ of BRE did not change cell morphology. These results indicate that BRE is not significantly cytotoxic to $\mathrm{HaCaT}$ cells or HDF. Therefore, $5-100 \mu \mathrm{g} / \mathrm{ml}$ of BRE was used for the subsequent experiments. 
A

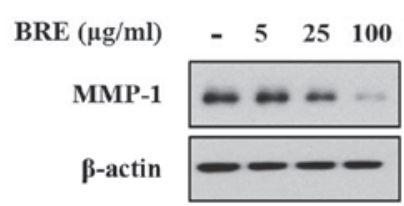

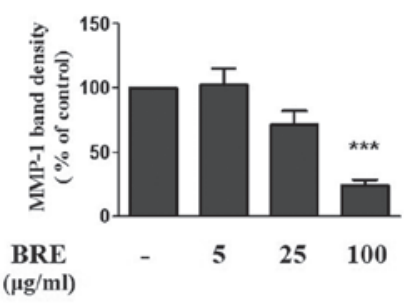

$(\mu \mathrm{g} / \mathrm{ml})$

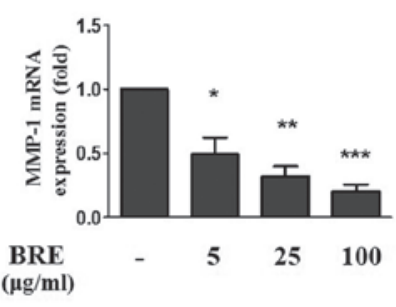

$(\mu \mathrm{g} / \mathrm{ml})$

B
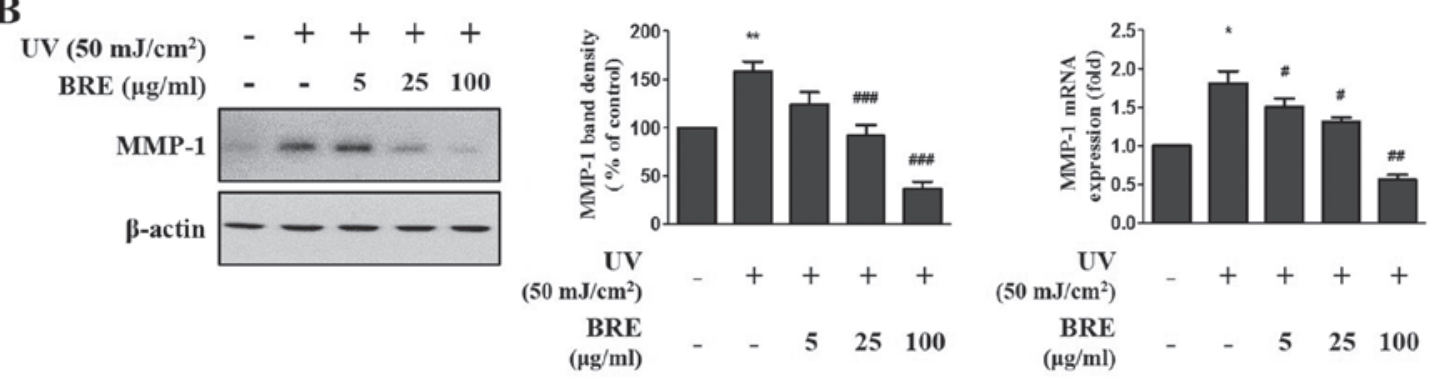

Figure 2. The inhibition effect of BRE on MMP-1 expression in HaCaT cells. HaCaT cells were post-treated with the indicated concentration of BRE for $48 \mathrm{~h}$, (A) without or (B) with UV irradiation $\left(50 \mathrm{~mJ} / \mathrm{cm}^{2}\right)$. The MMP-1 protein level in the conditioned medium was investigated by western blot analysis and relative band density was analyzed using ImageJ software. Actin was used as endogenous control. The MMP-1 mRNA level was analyzed by RT-qPCR, respectively. 36B4 mRNA was used to normalize each mRNA expression level. The bar graphs show the mean \pm SEM of three independent experiments. "P $<0.05$, "* $\mathrm{P}<0.01$, ${ }^{* * *} \mathrm{P}<0.001$ compared with the non-irradiated control cells. ${ }^{\# \mathrm{P}}<0.05,{ }^{\# \#} \mathrm{P}<0.01,{ }^{\# \# \#} \mathrm{P}<0.001$ compared with the UV-irradiated control cells. BRE, black rice extract; MMP, matrix metalloproteinase; UV, ultraviolet; RT-qPCR, reverse transcription-quantitative PCR.

A

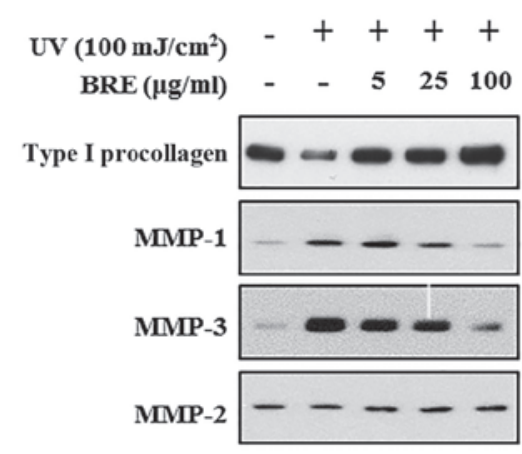

B

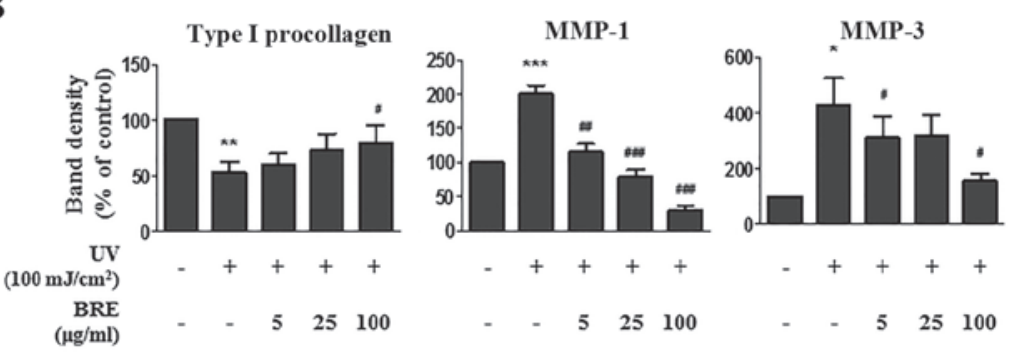

C

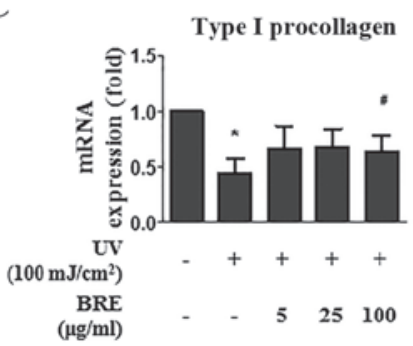

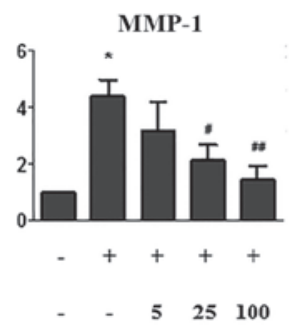

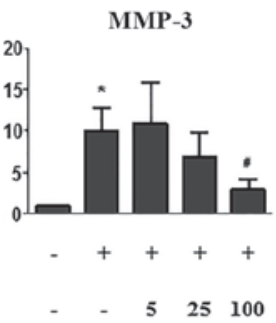

Figure 3. The effect of BRE on MMPs and procollagen expression in HDF. HDF were exposed to $100 \mathrm{~mJ} / \mathrm{cm}^{2}$ of UV irradiation and post-treated with BRE. The MMPs and procollagen expression levels were then examined. (A) The western blot shows the MMP-1, MMP-2, MMP-3, and procollagen protein levels in the conditioned medium from the UV-irradiated HDF treated with BRE for $48 \mathrm{~h}$. (B) Relative band density was analyzed using ImageJ software. MMP-2 was used as endogenous control. (C) The MMP-1, MMP-3, and procollagen mRNA levels in the UV-exposed HDF, following treatment with the indicated concentration of BRE for $48 \mathrm{~h}$, were assessed using RT-qPCR. 36B4 mRNA was used to normalize each mRNA expression level. The graphs show the mean \pm SEM of three independent experiments. ${ }^{~} \mathrm{P}<0.05,{ }^{* *} \mathrm{P}<0.01,{ }^{* * *} \mathrm{P}<0.001$ compared with the non-irradiated control cells. ${ }^{\#} \mathrm{P}<0.05,{ }^{\# \#} \mathrm{P}<0.01,{ }^{\# \# \#} \mathrm{P}<0.001$ compared with the UV-irradiated control cells. BRE, black rice extract; MMP, matrix metalloproteinase; HDF, human dermal fibroblasts; UV, ultraviolet; RT-qPCR, reverse transcription-quantitative PCR.

BRE inhibits MMP-1 expression in HaCaT cells. To determine the effect of BRE on MMP-1 production in HaCaT cells, the cells were post-treated with BRE for $48 \mathrm{~h}$, with or without UV irradiation. The basal level of MMP-1 expression was decreased to $24 \%$ in $100 \mu \mathrm{g} / \mathrm{ml} \mathrm{BRE}$ treated cells compared with non-treated cells by western blot analysis. Additionally, MMP-1 mRNA level also showed similar result. BRE reduced basal MMP-1 expression in a dose-dependent manner (0.5 $\pm 0.2,0.3 \pm 0.1$, and $0.2 \pm 0.1$-fold, respectively) (Fig. 2A). Furthermore, BRE ameliorated UV-induced MMP-1 expres- 

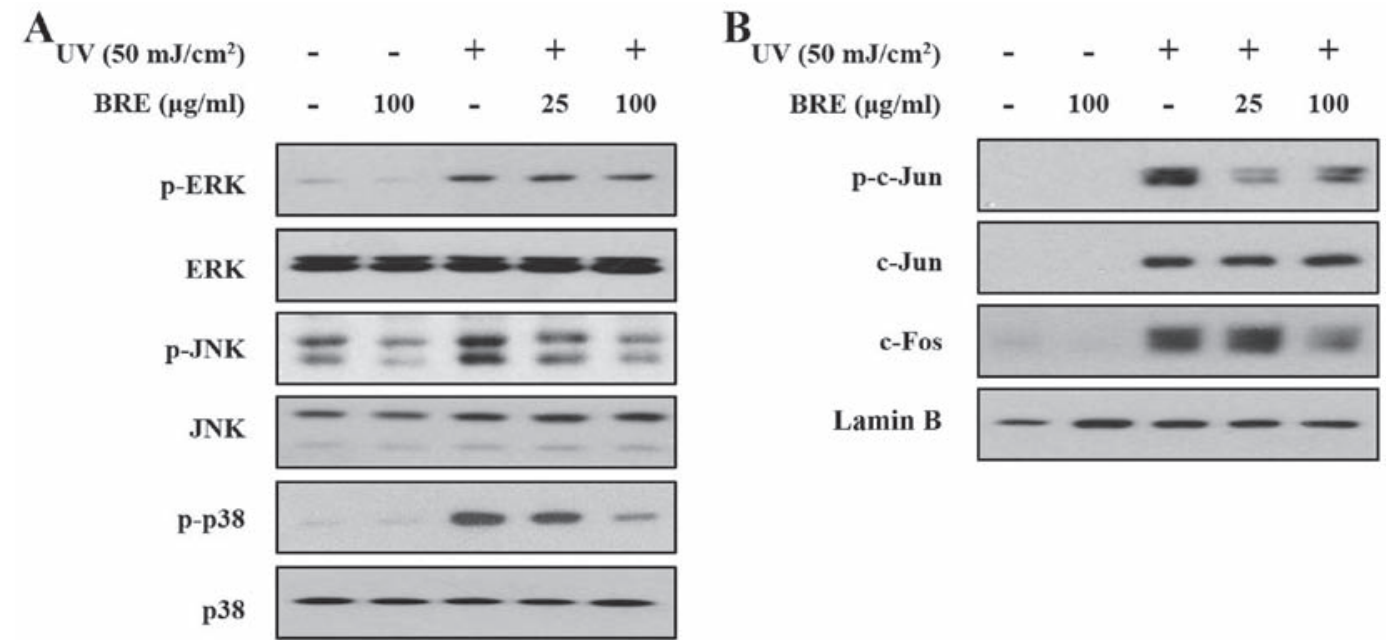

Figure 4. The effect of BRE on UV-induced MAPK signaling, and AP-1 (c-Jun/c-Fos) activity in HaCaT cells. The effects of BRE on UV-induced MAPK signaling, and AP-1 activity were examined. The HaCaT cells were post-treated with the indicated concentration of BRE for 15 min, with or without UV irradiation $\left(50 \mathrm{~mJ} / \mathrm{cm}^{2}\right)$. (A) The phosphorylation status of ERK, JNK, and p38 was then assessed using western blot analysis. (B) UV-irradiated or non-irradiated $\mathrm{HaCaT}$ cells were also post-treated with BRE for $4 \mathrm{~h}$, and the nuclear levels of phospho-c-Jun, c-Jun and c-Fos were analyzed. The blots shown are representative images of three independent experiments. BRE, black rice extract; UV, ultraviolet; MAPK, mitogen-activated protein kinase; AP-1, activator protein-1; ERK, extracellular signal-regulated kinase; JNK, c-Jun N-terminal kinase.

sion (158\% of control) in a concentration-dependent manner (25, and $100 \mu \mathrm{g} / \mathrm{ml} \mathrm{BRE} \mathrm{showed} 92$ and $36 \%$ of control, respectively). The MMP-1 mRNA level was $1.8 \pm 0.3$-fold higher in the UV-exposed cells than in the control cells. However,

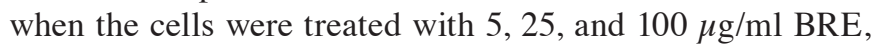
the expression of MMP-1 was markedly suppressed (1.5 \pm 0.2 , 1.3 \pm 0.1 , and 0.5 \pm 0.1 -fold, respectively) (Fig. 2B).

BRE suppresses $U V$-induced MMP-1 and MMP-3 expression, and decreased procollagen expression in $H D F$. To investigate the effect of BRE in UV-irradiated HDF, the cells were post-treated with BRE for $48 \mathrm{~h}$ after UV irradiation $\left(100 \mathrm{~mJ} / \mathrm{cm}^{2}\right)$. The amount of procollagen and MMPs (MMP-1, MMP-2, and MMP-3) secreted into the culture medium was analyzed, and the mRNA levels were analyzed using total RNA. The results showed that MMP-1 and MMP-3 secretion dramatically increased in the UV-irradiated HDF compared to that in the control cells (200 and $430 \%$ of the control, respectively), but treatment with 5,25 , or $100 \mu \mathrm{g} / \mathrm{ml}$ of BRE inhibited UV-induced MMP-1 (115, 80 and 31\% of the control, respectively) and MMP-3 production (315, 320 and $155 \%$ of the control, respectively). Furthermore, UV-induced suppression of procollagen production (46\% of control) was recovered in $100 \mu \mathrm{g} / \mathrm{ml}$ of BRE treated cells (80\% of control) (Fig. 3A and 3B). The MMP-2 level was unaffected, and served as a loading control. The expression level of MMP-1 in the UV irradiated cells was 4.4 1.0 -fold higher than that in the non-irradiated cells. However, treatment with 25 and $100 \mu \mathrm{g} / \mathrm{ml}$ BRE significantly reduced the MMP-1 expression level to just $2.1 \pm 1.0$ and $1.5 \pm 0.8$-fold higher than the control value, respectively. The MMP-3 expression level was also significantly upregulated by UV irradiation (10.0 44.9 -fold). However, the cells treated with $100 \mu \mathrm{g} / \mathrm{ml}$ of BRE showed significantly inhibited MMP-3 expression (2.9 \pm 2.0 -fold). Next, we investigated the change in procollagen production following $\mathrm{UV}$ and BRE treatment. While type I procollagen production was suppressed $(0.4 \pm 0.3$-fold) in the HDF following UV exposure, treatment with $100 \mu \mathrm{g} / \mathrm{ml} \mathrm{BRE} \mathrm{increased} \mathrm{the} \mathrm{type} \mathrm{I} \mathrm{procollagen}$ protein and mRNA levels (0.6 \pm 0.3 -fold) in the HDF (Fig. 3C).

Effect of BRE on UV-induced MAPK signaling and AP-1 activity. To elucidate whether MAPK signaling pathways are involved in the attenuation of UV-induced MMP-1 expression in $\mathrm{HaCaT}$ cells, the cells were treated with the indicated concentrations of BRE for $4 \mathrm{~h}$ before UV irradiation $\left(50 \mathrm{~mJ} / \mathrm{cm}^{2}\right)$. As shown in Fig. 4A, UV irradiation significantly increased the phosphorylation of ERK, JNK, and p38 within 15 min. Post-treatment with BRE diminished the UV-induced phosphorylation of JNK and p38 in a dose-dependent manner, but ERK phosphorylation was unaffected.

AP-1 is a transcription factor composed of c-Jun and c-Fos subunits $(10,25)$. Next, we analyzed c-Jun phosphorylation and c-Fos expression in nuclear extracts from the UV-irradiated HaCaT cells. The cells were irradiated with UV, and then incubated for $4 \mathrm{~h}$ with the indicated concentrations of BRE. Although UV exposure increased c-Jun and c-Fos expression, and c-Jun phosphorylation, BRE treatment suppressed c-Jun phosphorylation, and c-Fos expression in the nucleus (Fig. 4B).

$B R E$ reduces $U V$-induced intracellular ROS generation. To determine whether BRE can reduce UV-induced ROS production, HaCaT cells were pre-treated with BRE or NAC for $1 \mathrm{~h}$ before UV irradiation $\left(50 \mathrm{~mJ} / \mathrm{cm}^{2}\right)$. The intracellular ROS levels measured using DCF-DA assay were $82.0 \pm 7.6 \%$ and $73.8 \pm 8.0 \%$ of the control value, following treatment

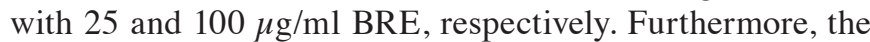
UV-irradiated cells displayed dramatically increased ROS generation $(234.0 \pm 9.6 \%)$ when compared with the control, whereas treatment with 25 and $100 \mu \mathrm{g} / \mathrm{ml}$ BRE significantly attenuated the intracellular ROS level to $183.0 \pm 10.2 \%$ and $169.2 \pm 5.9 \%$, respectively (Fig. 5A). Under the same experimental conditions, a decrease in the ROS level following 
A

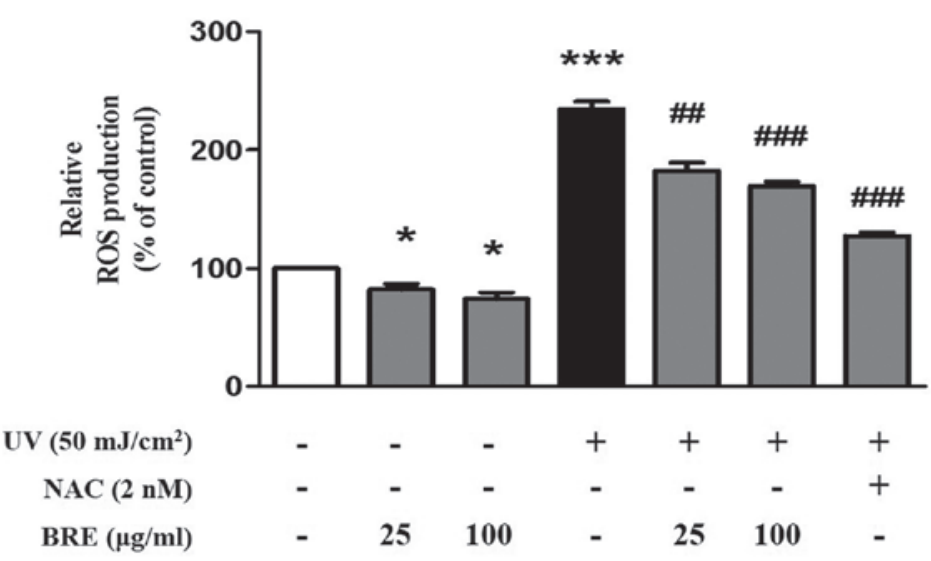

B

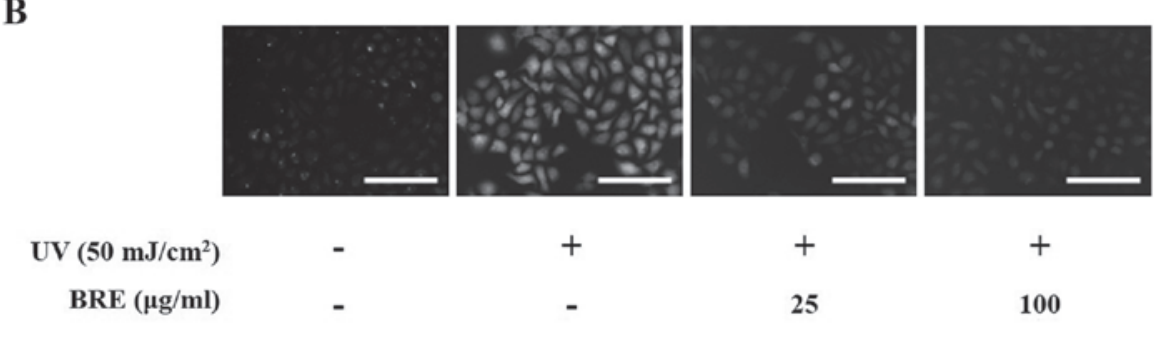

C

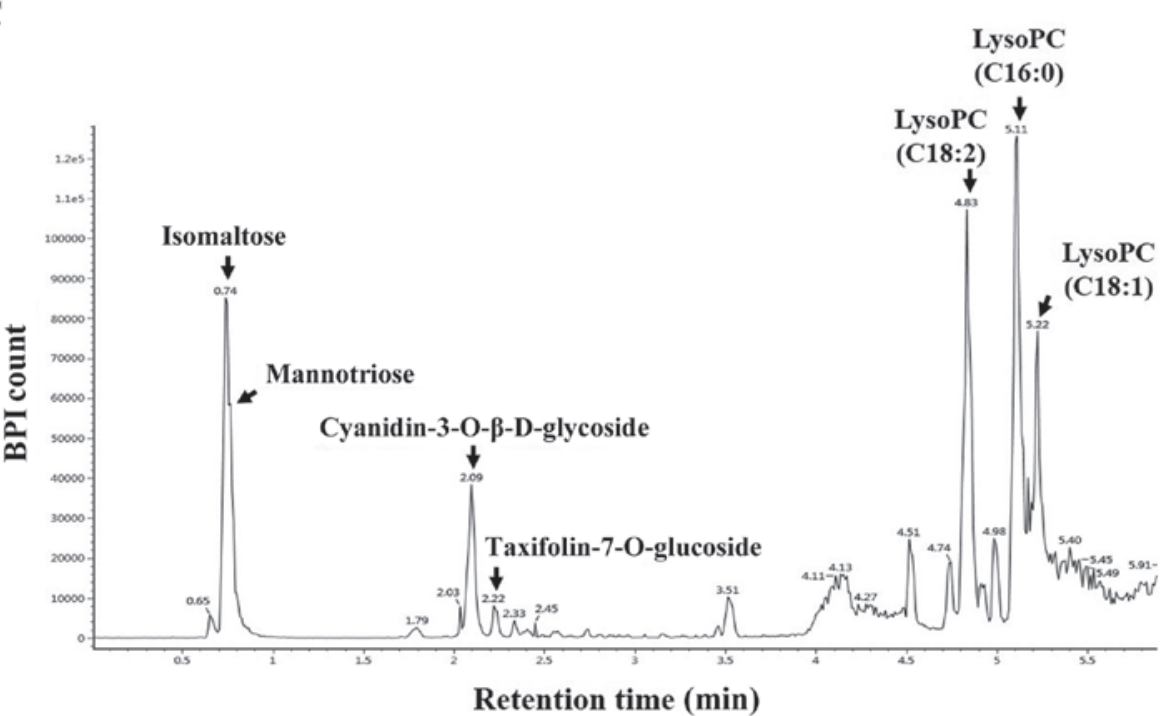

Figure 5. BRE reduced intracellular oxidative stress in $\mathrm{HaCaT}$ cells. The cells were pre-treated with BRE or NAC for $1 \mathrm{~h}$ before UV exposure, and the relative ROS levels were analyzed using DCF-DA. (A) The difference in DCF fluorescence generated from DCF-DA by intracellular ROS was measured using a multilabel plate reader, and (B) florescence microscopy. (C) BRE was analyzed using UPLC-Q-TOF MS profiles. The graph shows the mean \pm SEM of at least three experiments. ${ }^{*} \mathrm{P}<0.05,{ }^{* * *} \mathrm{P}<0.001$ compared with the non-irradiated control cells. ${ }^{\# \#} \mathrm{P}<0.01,{ }^{\# \# "} \mathrm{P}<0.001$ compared with the UV-irradiated control cells. Scale bar indicates $200 \mu \mathrm{m}$. BRE, black rice extract; NAC, $N$-acetylcysteine; UV, ultraviolet; ROS, reactive oxygen species, DCF-DA, 2'7'-dichlorofluorescein diacetate.

BRE treatment was also observed using fluorescence microscopy (Fig. 5B). Analysis of the components in BRE using the optimized UPLC-Q-TOF MS method showed that polysaccharides such as isomaltose and mannotriose were detected at $0.74 \mathrm{~min}$ and lysophosphatidylcholine (LysoPC) components at $4.83,5.11$ and $5.22 \mathrm{~min}$. The flavonoid components, cyanidin-3-O- $\beta$-D-glycoside (C3G), known as an anthocyanin and taxifolin-7-O-glucoside (T7G), were detected at 2.09 and $2.22 \mathrm{~min}$, respectively (Fig. 5C). These results indicated that the photoprotective effect of BRE in skin cells may be attributed to antioxidant effects possibly by flavonoids.

\section{Discussion}

UV-induced DNA damage and ROS initiate various changes in expression of genes, which are involved in inflammatory responses that lead to pre-mature skin aging, known as 'photoaging' (26,27). Therefore, the application of antioxidants and/or anti-inflammatory compounds is thought to enhance 
resistance to photoaging. Previous investigations have suggested that BRE has antioxidative effects in HepG2 cells and C57BL/6 mice, through the induction of superoxide dismutase and catalase activity (13). Furthermore, anthocyanins from black rice bran have been shown to have ROS-scavenging activity in vitro (28). BRE also relieves skin inflammation in a chemical-induced inflammatory mouse model (15). However, the precise effects and underlying mechanisms of BRE in UV-induced responses in skin cells are still unknown.

In the present study, we demonstrated that BRE has potent photoprotective effects against UV-irradiated changes in skin cells, possibly via ROS/MAPK signaling pathways. UV irradiation induces MMP expression, which leads to the breakdown of collagen, a dominant component of connective tissue (29,30). We demonstrated that BRE inhibits UV-induced MMP-1 expression in HaCaT cells, and MMP-1 and MMP-3 expression in HDF.

In the skin, collagen is necessary to maintain resiliency and strength, and decreased collagen expression is observed in photoaged skin $(31,32)$. In the present study, UV-exposed HDF showed a reduced level of type I procollagen, which was recovered by BRE treatment. Our findings indicate that BRE could prevent or rescue UV-induced ECM alterations via a dual pathway involving inhibition of MMP expression and increase of procollagen expression.

Oxidative stress induced by UV irradiation is one of the pivotal triggers of MMP-1 and MMP-3 upregulation by both the AP-1 dependent and independent (p38 activity) pathways in HDF (33). Thus, reducing ROS levels could be an effective strategy to prevent photo-damage $(26,27,34)$. In the present study, BRE significantly reduced intracellular ROS generation in $\mathrm{HaCaT}$ cells. In addition, BRE inhibited UV-induced AP-1 activity (c-Jun/c-Fos), and MAPK (JNK/p38) signaling, possibly owing to its antioxidative effects.

Botanical phenolic acids and flavonoids exert antioxidant effects and these are commonly used in the prevention of photoaging $(35,36)$. Black rice contains abundant flavonoids and polyphenols, including cyanidin-3-O-glycoside chloride $(\mathrm{C} 3 \mathrm{G})$, peonidin-3-O-glucoside chloride, and ferulic acid (13,37). C3G is a typical anthocyanin, which shows antioxidative effects in various conditions (38-40). In addition, taxifolin has been reported to be detected in black rice bran (41) and has antioxidant properties $(42,43)$. UPLC-Q-TOF MS result showed that BRE here contains considerable amounts of $\mathrm{C} 3 \mathrm{G}$ and $\mathrm{T} 7 \mathrm{G}$. Therefore, the antioxidative and protective effect of BRE on UV-irradiated skin cells are thought to be attributed to flavonoids, such as $\mathrm{C} 3 \mathrm{G}$ or $\mathrm{T} 7 \mathrm{G}$ in BRE.

One of the most important protective mechanisms of flavonoids is their antioxidative ability through the activation of Nrf2-dependent genes. Under normal physiological conditions, inactive Nrf2 is located in the cytoplasm with its inhibitor Keap1. Under high ROS conditions, Nrf2 is released from Keap1 and moved into the nucleus, regulating the expression of downstream target genes via antioxidant response element (ARE) binding sites in the promoter (44). Flavonoids are potent inducers of the ARE/Nrf2/Keap1 signaling pathway, and the anthocyanin is the most prominent among the flavonoids $(45,46)$. Thus, the antioxidant activity through Nrf2 activation by anthocyanin contained in BRE is also a possible mechanism.
In conclusion, BRE attenuates markers of photoaging including reduction of collagen and increases of MMPs in skin cells. The underlying mechanism involved in these beneficial effects could be the inhibition of ROS generation and AP-1 activation in vitro. Further study employing proteomic analysis by mass spectroscopy is warranted to determine other factors in addition to MMP-1 and collagen. Additionally, if stability, safety, and efficacy are demonstrated in human clinical studies, BRE could be used as a cosmetic ingredient for preventing photoaging of the skin.

\section{Acknowledgements}

Not applicable.

\section{Funding}

This research was supported by a grant from the Korea Health Technology R\&D Project through the Korea Health Industry Development Institute (KHIDI), funded by the Ministry of Health and Welfare, Republic of Korea (grant nos. HI12C1723 and HI14C1277).

\section{Availability of data and material}

The datasets used and/or analyzed during the current study are available from the corresponding author on reasonable request.

\section{Authors' contributions}

MH, JSB and DHL designed the study and performed the experiments. HSS provided the black rice extract and analyzed UPLC-Q-TOP. JJB performed the cell viability assay and was involved in drafting the article. JHC had full access to all the data, and takes full responsibility for the integrity of data and the accuracy of data analysis. All authors read and approved the final manuscript.

\section{Ethics approval and consent to participate}

Not applicable.

\section{Consent for publication}

Not applicable.

\section{Competing interests}

The authors declare that they have no competing interests.

\section{References}

1. Bikle DD: The vitamin D receptor: A tumor suppressor in skin. Adv Exp Med Biol 810: 282-302, 2014.

2. Berneburg M, Plettenberg $\mathrm{H}$ and Krutmann J: Photoaging of human skin. Photodermatol Photoimmunol Photomed 16: 239-244, 2000.

3. Ichihashi M, Ueda M, Budiyanto A, Bito T, Oka M, Fukunaga M, Tsuru K and Horikawa T: UV-induced skin damage. Toxicology 189: 21-39, 2003.

4. Yamazaki S, Nishioka A, Kasuya S, Ohkura N, Hemmi H, Kaisho T, Taguchi O, Sakaguchi S and Morita A: Homeostasis of thymus-derived Foxp3+ regulatory T cells is controlled by ultraviolet B exposure in the skin. J Immunol 193: 5488-5497, 2014. 
5. Brenneisen P, Sies H and Scharffetter-Kochanek K: Ultraviolet-B irradiation and matrix metalloproteinases: From induction via signaling to initial events. Ann N Y Acad Sci 973: 31-43, 2002.

6. Fisher GJ, Wang ZQ, Datta SC, Varani J, Kang S and Voorhees JJ: Pathophysiology of premature skin aging induced by ultraviolet light. N Engl J Med 337: 1419-1428, 1997.

7. BaldT,QuastT,Landsberg J,RogavaM,GloddeN,Lopez-RamosD, Kohlmeyer J, Riesenberg S, van den Boorn-Konijnenberg D, Hömig-Hölzel C, et al: Ultraviolet-radiation-induced inflammation promotes angiotropism and metastasis in melanoma. Nature 507: 109-113, 2014

8. Bowden GT: Prevention of non-melanoma skin cancer by targeting ultraviolet-B-light signalling. Nat Rev Cancer 4: 23-35, 2004.

9. Rigel DS: Cutaneous ultraviolet exposure and its relationship to the development of skin cancer. J Am Acad Dermatol 58 (Suppl 2): S129-S132, 2008.

10. Fisher GJ and Voorhees JJ: Molecular mechanisms of photoaging and its prevention by retinoic acid: Ultraviolet irradiation induces MAP kinase signal transduction cascades that induce Ap-1-regulated matrix metalloproteinases that degrade human skin in vivo. J Investig Dermatol Symp Proc 3: 61-68, 1998.

11. Angel P, Szabowski A and Schorpp-Kistner M: Function and regulation of AP-1 subunits in skin physiology and pathology. Oncogene 20: 2413-2423, 2001.

12. Zhang H, Shao Y, Bao J and Beta T: Phenolic compounds and antioxidant properties of breeding lines between the white and black rice. Food Chem 172: 630-639, 2015.

13. Chiang AN, Wu HL, Yeh HI, Chu CS, Lin HC and Lee WC: Antioxidant effects of black rice extract through the induction of superoxide dismutase and catalase activities. Lipids 41: 797-803, 2006.

14. Wang Q, Han P, Zhang M, Xia M, Zhu H, Ma J, Hou M, Tang Z and Ling W: Supplementation of black rice pigment fraction improves antioxidant and anti-inflammatory status in patients with coronary heart disease. Asia Pac J Clin Nutr 16 (Suppl 1): 295-301, 2007.

15. Choi SP, Kim SP, Kang MY, Nam SH and Friedman M: Protective effects of black rice bran against chemically-induced inflammation of mouse skin. J Agric Food Chem 58: 10007-10015, 2010.

16. Xia X, Ling W, Ma J, Xia M, Hou M, Wang Q, Zhu H and Tang Z: An anthocyanin-rich extract from black rice enhances atherosclerotic plaque stabilization in apolipoprotein E-deficient mice. J Nutr 136: 2220-2225, 2006.

17. Chen PN, Kuo WH, Chiang CL, Chiou HL, Hsieh YS and Chu SC: Black rice anthocyanins inhibit cancer cells invasion via repressions of MMPs and u-PA expression. Chem Biol Interact 163: 218-229, 2006.

18. Fan MJ, Wang IC, Hsiao YT, Lin HY, Tang NY, Hung TC, Quan C, Lien JC and Chung JG: Anthocyanins from black rice (Oryza sativa L.) demonstrate antimetastatic properties by reducing MMPs and $\mathrm{NF}-\kappa \mathrm{B}$ expressions in human oral cancer CAL 27 cells. Nutr Cancer 67: 327-338, 2015

19. Choi SP, Kim SP, Nam SH and Friedman M: Antitumor effects of dietary black and brown rice brans in tumor-bearing mice: Relationship to composition. Mol Nutr Food Res 57: 390-400, 2013.

20. Hui C, Bin Y, Xiaoping Y, Long Y, Chunye C, Mantian M and Wenhua L: Anticancer activities of an anthocyanin-rich extract from black rice against breast cancer cells in vitro and in vivo. Nutr Cancer 62: 1128-1136, 2010.

21. Miyazawa M, Oshima T, Koshio K, Itsuzaki Y and Anzai J: Tyrosinase inhibitor from black rice bran. J Agric Food Chem 51: 6953-6956, 2003.

22. Sim GS, Lee DH, Kim JH, An SK, Choe TB, Kwon TJ, Pyo HB and Lee BC: Black rice (Oryza sativa L. var. japonica) hydrolyzed peptides induce expression of hyaluronan synthase 2 gene in HaCaT keratinocytes. J Microbiol Biotechnol 17: 271-279, 2007

23. Jin CL, Oh JH, Han M, Shin MK, Yao C, Park CH, Jin ZH and Chung JH: UV irradiation-induced production of monoglycosylated biglycan through downregulation of xylosyltransferase 1 in cultured human dermal fibroblasts. J Dermatol Sci 79: 20-29, 2015.

24. Bae JS, Han M, Yao C and Chung JH: Chaetocin inhibits IBMX-induced melanogenesis in B16 F10 mouse melanoma cells through activation of ERK. Chem Biol Interact 245: 66-71, 2016.

25. Silvers AL, Bachelor MA and Bowden GT: The role of JNK and p38 MAPK activities in UVA-induced signaling pathways leading to AP-1 activation and c-Fos expression. Neoplasia 5: $319-329,2003$
26. Natarajan VT, Ganju P, Ramkumar A, Grover R and Gokhale RS: Multifaceted pathways protect human skin from UV radiation. Nat Chem Biol 10: 542-551, 2014.

27. Pillai S, Oresajo C and Hayward J: Ultraviolet radiation and skin aging: Roles of reactive oxygen species, inflammation and protease activation, and strategies for prevention of inflammation-induced matrix degradation - a review. Int J Cosmet Sci 27: 17-34, 2005.

28. Kaneda I, Kubo F and Sakurai H: Antioxidative compounds in the extracts of black rice brans. J Health Sci 52: 495-511, 2006.

29. Jabłońska-Trypuć A, Matejczyk M and Rosochacki S: Matrix metalloproteinases (MMPs), the main extracellular matrix (ECM) enzymes in collagen degradation, as a target for anticancer drugs. J Enzyme Inhib Med Chem 31: 177-183, 2016.

30. Quan T, Qin Z, Xia W, Shao Y, Voorhees JJ and Fisher GJ: Matrix-degrading metalloproteinases in photoaging. J Investig Dermatol Symp Proc 14: 20-24, 2009.

31. Fisher GJ, Datta S, Wang Z, Li XY, Quan T, Chung JH, Kang S and Voorhees JJ: c-Jun-dependent inhibition of cutaneous procollagen transcription following ultraviolet irradiation is reversed by all-trans retinoic acid. J Clin Invest 106: 663-670, 2000.

32. Fisher GJ, Kang S, Varani J, Bata-Csorgo Z, Wan Y, Datta S and Voorhees JJ: Mechanisms of photoaging and chronological skin aging. Arch Dermatol 138: 1462-1470, 2002.

33. Reunanen N, Li SP, Ahonen M, Foschi M, Han J and Kähäri VM: Activation of p38 alpha MAPK enhances collagenase-1 (matrix metalloproteinase (MMP)-1) and stromelysin-1 (MMP-3) expression by mRNA stabilization. J Biol Chem 277: 32360-32368, 2002.

34. Shin MH, Rhie GE, Kim YK, Park CH, Cho KH, Kim KH, Eun $\mathrm{HC}$ and Chung JH: $\mathrm{H}_{2} \mathrm{O}_{2}$ accumulation by catalase reduction changes MAP kinase signaling in aged human skin in vivo. J Invest Dermatol 125: 221-229, 2005

35. Jadoon S, Karim S, Bin Asad MH, Akram MR, Khan AK, Malik A, Chen C and Murtaza G: Anti-aging potential of phytoextract loaded-pharmaceutical creams for human skin cell longetivity. Oxid Med Cell Longev 2015: 709628, 2015.

36. Nichols JA and Katiyar SK: Skin photoprotection by natural polyphenols: Anti-inflammatory, antioxidant and DNA repair mechanisms. Arch Dermatol Res 302: 71-83, 2010.

37. Sumczynski D, Kotásková E, Družbíková H and Mlček J: Determination of contents and antioxidant activity of free and bound phenolics compounds and in vitro digestibility of commercial black and red rice (Oryza sativa L.) varieties. Food Chem 211: 339-346, 2016

38. Kim MK, Kim HA, Koh K, Kim HS, Lee YS and Kim YH: Identification and quantification of anthocyanin pigments in colored rice. Nutr Res Pract 2: 46-49, 2008.

39. Min B, McClung AM and Chen MH: Phytochemicals and antioxidant capacities in rice brans of different color. J Food Sci 76: C117-C126, 2011.

40. Zhang MW, Zhang RF, Zhang FX and Liu RH: Phenolic profiles and antioxidant activity of black rice bran of different commercially available varieties. J Agric Food Chem 58: 7580-7587, 2010.

41. Sriseadka T, Wongpornchai S and Rayanakorn M: Quantification of flavonoids in black rice by liquid chromatography-negative electrospray ionization tandem mass spectrometry. J Agric Food Chem 60: 11723-11732, 2012.

42. Rice-Evans CA, Miller NJ and Paganga G: Structure-antioxidant activity relationships of flavonoids and phenolic acids. Free Radic Biol Med 20: 933-956, 1996

43. Sun X, Chen RC, Yang ZH, Sun GB, Wang M, Ma XJ, Yang LJ and Sun XB: Taxifolin prevents diabetic cardiomyopathy in vivo and in vitro by inhibition of oxidative stress and cell apoptosis. Food Chem Toxicol 63: 221-232, 2014.

44. Surh YJ, Kundu JK and Na HK: Nrf2 as a master redox switch in turning on the cellular signaling involved in the induction of cytoprotective genes by some chemopreventive phytochemicals. Planta Med 74: 1526-1539, 2008.

45. Ji LL, Sheng YC, Zheng ZY, Shi L and Wang ZT: The involvement of p62-Keap1-Nrf2 antioxidative signaling pathway and JNK in the protection of natural flavonoid quercetin against hepatotoxicity. Free Radic Biol Med 85: 12-23, 2015.

46. Hwang YP, Choi JH, Yun HJ, Han EH, Kim HG, Kim JY, Park BH, Khanal T, Choi JM, Chung YC and Jeong HG: Anthocyanins from purple sweet potato attenuate dimethylnitrosamine-induced liver injury in rats by inducing Nrf2-mediated antioxidant enzymes and reducing COX-2 and iNOS expression. Food Chem Toxicol 49: 93-99, 2011. 